Article

\title{
Characterization and Thermal Stability of Acetylated Slicewood Production by Alkali-Catalyzed Esterification
}

\author{
Ke-Chang Hung, Chen-Ning Yang, Teng-Chun Yang, Tung-Lin Wu, Yong-Long Chen and \\ Jyh-Horng Wu * \\ Department of Forestry, National Chung Hsing University, Taichung 402, Taiwan; \\ d9833004@mail.nchu.edu.tw (K.-C.H.); abcyjn96@hotmail.com (C.-N.Y.); tcyang.04@nchu.edu.tw (T.-C.Y.); \\ tonywuwu22@gmail.com (T.-L.W.); d9733202@mail.nchu.edu.tw (Y.-L.C.) \\ * Correspondence: eric@nchu.edu.tw; Tel.: +886-4-2284-0345 (ext. 136); Fax: +886-4-2285-1308 \\ Academic Editor: Mark Evans
}

Received: 7 March 2017; Accepted: 4 April 2017; Published: 7 April 2017

\begin{abstract}
This study was compared and characterized two different alkali (potassium carbonate (PC) and potassium acetate (PA))-catalyzed acetylations of slicewood with vinyl acetate (VA) by a vapor phase reaction. The results revealed that the esterification reaction between VA and the hydroxyl groups of slicewood could be improved by using PC or PA as a catalyst. Additionally, a significant weight percent gain was obtained after VA acetylation with $5 \%$ of catalyst. Furthermore, the reactivity of the cellulose hydroxyl groups for VA acetylation was more pronounced at the C2 reactive site compared to acetylation with acetic anhydride. On the other hand, the apparent activation energy of thermal decomposition between $10 \%$ and $70 \%$ conversion is $174-183,194-200$, and $183-186 \mathrm{~kJ} / \mathrm{mol}$ for unmodified slicewood and VA-acetylated slicewood with PC and PA, respectively. Accordingly, the thermal stability of the slicewood could be effectively enhanced by VA acetylation, especially for using the PC as a catalyst.
\end{abstract}

Keywords: acetylation; slicewood; vinyl acetate; thermal decomposition kinetic; apparent activation energy

\section{Introduction}

In recent years, slicewood and veneer have become a more important part of the wood market because the gradual disappearance of global forest resources has let the supply of large trees to diminish [1]. However, slicewood or veneers are often sourced from fast-grown plantation forests, with properties and durability inferior to those sourced from natural-growth forests. Several physical and chemical methods, such as acetylation, heat treatment, and sol-gel treatment, have been used to improve the properties and durability of wood [2-5]. Among these known approaches, acetylation with acetic anhydride (AA) is one of the best chemical modifications, with corresponding products having already been commercialized in the USA, Europe, and Japan [6-9].

The conventional acetylation process is not only time-consuming, but also requires large quantities of the modifying agent. According to Yang et al. [10], wood acetylation with AA using a vapor phase reaction could reduce the reagent consumption. However, using AA as a reactant has a main drawback of generating acetic acid as a by-product during the reaction, which results in undesirable odors and is difficult to remove from wood after acetylation due to its high boiling point (ca. $\left.78{ }^{\circ} \mathrm{C}\right)[3,6,7,11,12]$. More recently, Jebrane and Sèbe showed that wood was successfully acetylated by an alternative modifying agent using a vinyl acetate (VA) transesterification [12]. The main advantages of this approach are a non-acidic by-product and low boiling point $\left(21^{\circ} \mathrm{C}\right)$. However, very few studies have 
addressed wood acetylation with VA using a vapor phase reaction. Furthermore, there is very little information about the influence of catalyst types on the reactivity of VA and the physico-mechanical and viscoelastic properties of VA-acetylated wood.

On the other hand, the thermal stability of the acetylated wood is mostly estimated by thermogravimetric analyses (TGA) [5,13-15]. More recently, the "model-free" iso-conversion methods have been widely employed to determine the activation energy $\left(E_{\mathrm{a}}\right)$ of materials. These approaches allow the observation of the $E_{\mathrm{a}}$ dependence without assuming the reaction function and reaction order with the same conversion of the thermogravimetric (TG) curves estimated at different heating rates $[16,17]$. These models provide a quantitative evaluation of the thermal decomposition behavior and the stability of materials and provide reaction kinetics data over a broad temperature region $[17,18]$. However, the effect of the acetylation on the thermal decomposition kinetics of wood has not yet been assessed. The objective of this study was to compare and characterize slicewood that was VA-acetylated using potassium carbonate and potassium acetate catalysts by a vapor phase reaction. To the best of our knowledge, this is not only the first work addressing differences in VA-acetylated slicewood using different alkaline catalysts, but also the first work providing the thermal decomposition kinetics of acetylated slicewood by the model-free iso-conversional methods.

\section{Materials \& Methods}

\subsection{Materials}

Japanese cedar (Cryptomeria japonica D. Don) sapwood (20-30 years old) was supplied by the experimental forest of the National Taiwan University. The dimensions of the slicewood samples were $3 \mathrm{~mm}(\mathrm{R}) \times 12 \mathrm{~mm}(\mathrm{~T}) \times 58 \mathrm{~mm}(\mathrm{~L})$. Oven-dried wood specimens that had straight longitudinal grain, were free of defects, and had modulus of elasticity (MOE) values from 5.5 to $7.0 \mathrm{GPa}$ were selected for this study. All of the samples were used after extraction in a Soxhlet apparatus for $24 \mathrm{~h}$ with a 1:2 $(v / v)$ mixture of ethanol and toluene followed by washing with distilled water. The extracted slicewood was dried at $105^{\circ} \mathrm{C}$ for $12 \mathrm{~h}$, and the oven-dried weights were measured. Vinyl acetate (VA), acetic anhydride (AA), dimethylformamide (DMF), potassium acetate (PA) (Sigma-Aldrich Chemical Co, St. Louis, MO, USA), potassium carbonate (PC) (Merck Chemical Co., Darmstadt, Germany), and other chemicals and solvents used in this experiment were of the highest quality available.

\subsection{Acetylation}

The slicewood was impregnated with different concentrations $(0.05,0.1,0.25$, and $0.5 \mathrm{M})$ of PC or PA solutions under reduced pressure for $30 \mathrm{~min}$ and then impregnated under atmospheric pressure for another $1 \mathrm{~h}$. The impregnated samples were dried at $105^{\circ} \mathrm{C}$ for $12 \mathrm{~h}$. The catalyst content in the wood materials was calculated from the following equation:

$$
\text { Catalyst content }(\%)=\left[\left(\mathrm{w}_{1}-\mathrm{w}_{0}\right) / \mathrm{w}_{0}\right] \times 100
$$

where $\mathrm{w}_{0}$ and $\mathrm{w}_{1}$ are the weight of an oven-dried sample before and after immersion, respectively.

The impregnated slicewood was acetylated with VA using a vapor phase reaction. The reaction used $20 \mathrm{mmol}$ of VA and $20 \mathrm{~mL}$ of DMF per gram of oven-dried wood. All reactions were conducted at different temperatures $\left(78^{\circ} \mathrm{C}\right.$ and $\left.140^{\circ} \mathrm{C}\right)$ for $0-24 \mathrm{~h}$ to obtain acetylated slicewood samples with different degrees of modification. At the end of the reaction, the acetylated samples were washed with distilled water and Soxhlet-extracted with acetone for $8 \mathrm{~h}$. Finally, the acetylated samples were dried at $105{ }^{\circ} \mathrm{C}$ for $12 \mathrm{~h}$, and the oven-drying method was used to calculate the weight percent gain (WPG) of the acetylated samples. In addition, for comparison purposes, a conventional acetylation process with AA by vapor phase reaction was also performed in this study, following the detailed procedure described in our previous study [10]. 


\subsection{Flexural Properties}

The modulus of rupture (MOR) and modulus of elasticity (MOE) of the specimens were determined by a three-point static bending test with a loading speed of $1.28 \mathrm{~mm} / \mathrm{min}$ and a span of $48 \mathrm{~mm}$ (the specimen size was $3 \mathrm{~mm} \times 12 \mathrm{~mm} \times 58 \mathrm{~mm}$ ) according to the American society for testing and materials (ASTM) standard D790 [19]. The samples were oven-dried at $105^{\circ} \mathrm{C}$ for $12 \mathrm{~h}$ prior to testing. All tests were carried out in an air-conditioned room at $20^{\circ} \mathrm{C}$. Nine specimens were used for each determination.

\subsection{Dynamic Mechanical Analysis}

The dynamic viscoelastic properties of the slicewood samples were measured using a single-cantilever bending test (DMA 8000, PerkinElmer, Buckinghamshire, UK) at a heating rate of $5{ }^{\circ} \mathrm{C} / \mathrm{min}$ and a frequency of $1 \mathrm{~Hz}$. The storage modulus $\left(E^{\prime}\right)$ and loss modulus $\left(E^{\prime \prime}\right)$ were recorded over a temperature range of $-180^{\circ} \mathrm{C}$ to $300^{\circ} \mathrm{C}$. The dimensions of the samples were $30 \mathrm{~mm}(\mathrm{~L}) \times 12 \mathrm{~mm}(\mathrm{~T})$ with a thickness of $3 \mathrm{~mm}$.

\subsection{Attenuated Total Reflectance Fourier Transform Infrared (ATR-FTIR) Spectral Measurements}

ATR-FTIR spectra were recorded on a Spectrum 100 FTIR spectrometer (PerkinElmer, Buckinghamshire, UK) equipped with a deuterated triglycine sulfate (DTGS) detector and a MIRacle ATR accessory (Pike Technologies, Madison, WI, USA). The spectra were collected by co-adding 32 scans at a resolution of $4 \mathrm{~cm}^{-1}$ in the range of 650 to $4000 \mathrm{~cm}^{-1}$.

\subsection{Solid-State Cross-Polarization Magic Angle Spin (CP/MAS) Carbon-13 Nuclear Magnetic Resonance $\left({ }^{13} \mathrm{C}-\mathrm{NMR}\right)$ Analysis}

The powder samples were examined by $\mathrm{CP} / \mathrm{MAS}{ }^{13} \mathrm{C}-\mathrm{NMR}$. The spectra were recorded on a Bruker DSX-400WB FT-NMR spectrometer (Brucker, Bremen, Germany) with a sampling frequency of $100 \mathrm{MHz}$. The chemical shifts were calculated relative to tetramethylsilane (TMS).

\subsection{Thermogravimetric Analysis (TGA)}

A PerkinElmer Pyris 1 TG analyzer (Shelton, CT, USA) was used. Measurements of $3 \mathrm{mg}$ samples were carried out in a nitrogen atmosphere $(20 \mathrm{~mL} / \mathrm{min})$ from $50-600{ }^{\circ} \mathrm{C}$. The heating rate was set to 5 , $10,20,30$, and $40^{\circ} \mathrm{C} / \mathrm{min}$. The kinetic parameters were calculated based on the data obtained by the model-free iso-conversional methods. The conversion rate $\alpha$ is defined as:

$$
\alpha=\left(\mathrm{W}_{0}-\mathrm{W}_{t}\right) /\left(\mathrm{W}_{0}-\mathrm{W}_{\infty}\right)
$$

where $W_{0}$ is the initial weight of the sample, $W_{\infty}$ is the final residual weight, and $W_{t}$ is the weight of the oxidized or pyrolized sample at time $t$. The common iso-conversional methods used in this study include the methods of Friedman (Equation (3)), Flynn-Wall-Ozawa (F-W-O) (Equation (4)), the modified Coats-Redfern (C-R) (Equation (5)), and Starink (Equation (6)). The methods are represented by the following equations:

$$
\begin{gathered}
\ln (\mathrm{d} \alpha / \mathrm{d} t)=\ln [A f(\alpha)]-E_{\mathrm{a}} /(R T) \\
\log \beta=\log \left[A E_{\mathrm{a}} /(R g(\alpha))\right]-2.315-0.4567 E_{\mathrm{a}} /(R T) \\
\ln \left\{\beta /\left[T^{2}\left(1-2 R T / E_{\mathrm{a}}\right)\right]\right\}=\ln \left\{-A R /\left[E_{\mathrm{a}} \ln (1-\alpha)\right]\right\}-E_{\mathrm{a}} /(R T) \\
\ln \left(\beta / T^{1.8}\right)=C_{\mathrm{s}}-1.0037\left(E_{\mathrm{a}} / R T\right)
\end{gathered}
$$

where $\alpha$ is the conversion rate, $A$ is the pre-exponential factor $\left(\min ^{-1}\right), f(\alpha)$ is the reaction model, $E_{\mathrm{a}}$ is the apparent $E_{\mathrm{a}}(\mathrm{kJ} / \mathrm{mol}), R$ is the gas constant $\left(8.314 \mathrm{~J} / \mathrm{K} \cdot \mathrm{mol}^{-1}\right), T$ is the absolute temperature $(\mathrm{K}), \beta$ is the heating rate, $g(\alpha)$ is a function of the conversion, and $C_{\mathrm{s}}$ is a constant [16-18]. Therefore, 
for a given conversion, linear relationships are observed by plotting $\ln (\mathrm{d} \alpha / \mathrm{d} t), \log \beta, \ln \left(\beta / T^{2}\right)$, and $\ln \left(\beta / T^{1.8}\right)$ versus $1 / T$ at different heating rates; the $E_{\mathrm{a}}$ is calculated from the slope of the straight line [16-18].

In addition to $E_{\mathrm{a}}$, the reaction order is also an important parameter for the thermal decomposition of wood [17]. The reaction order in this study was calculated based on the Avrami theory (Equation (7)):

$$
\ln [-\ln (1-\alpha)]=\ln A-E_{\mathrm{a}} / R T-n \ln \beta
$$

where $n$ represents the reaction order. For a given temperature, a linear relationship is observed by plotting $\ln [-\ln (1-\alpha)]$ versus $\ln \beta$ at different temperature heating rates, and the reaction order is deduced from the slope of the line [17].

\subsection{Statistical Analyses}

All results were expressed as the means \pm standard deviation (SD). The significance of the differences was calculated using Scheffe's test; $p$ values $<0.05$ were considered to be significant.

\section{Results and Discussion}

\subsection{Effects of the Reaction Temperature, Reaction Time, and Catalyst Content}

The effects of several reaction parameters including reaction temperature, reaction time, and catalyst content on the weight percent gain (WPG) of the slicewood acetylation with VA were investigated. Figure 1A shows the WPG of the slicewood that was acetylated with VA in $5 \mathrm{wt} \%$ PC at 78 and $140{ }^{\circ} \mathrm{C}$ for $0-24 \mathrm{~h}$. The results clearly revealed that the change in WPG of the VA-acetylated slicewood at $78{ }^{\circ} \mathrm{C}$ was not significant. This phenomenon is likely caused by insufficient thermal energy for acetylation at the reaction temperature of $78^{\circ} \mathrm{C}$. When reaction temperature raised to $140{ }^{\circ} \mathrm{C}$, expectedly, the WPG of VA-acetylated slicewood increases up to around $9.0 \%$ at the reaction time of $3 \mathrm{~h}$. Once the reaction time reached $24 \mathrm{~h}$, the WPG achieved $13.4 \%$.
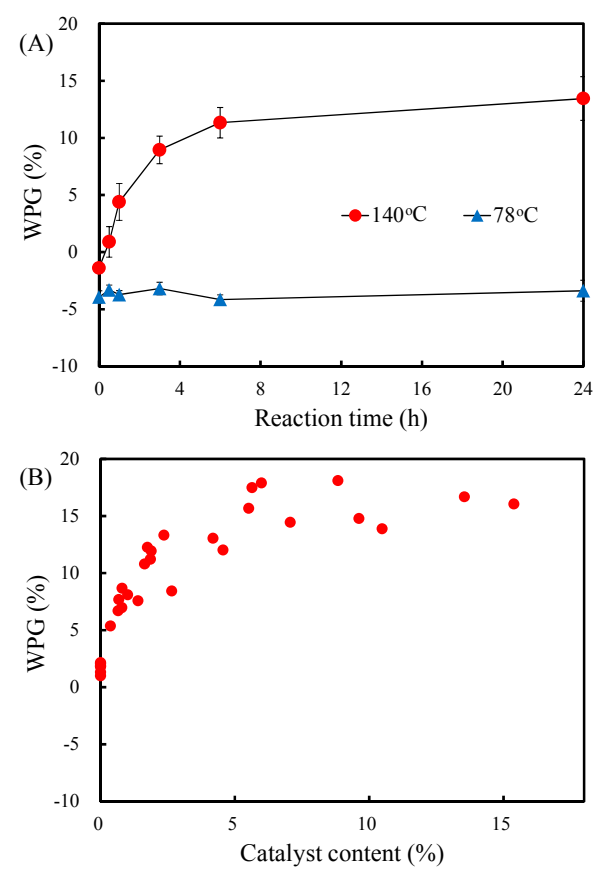

Figure 1. (A) The weight percent gain (WPG) of vinyl acetate (VA)-acetylated slicewood reacted at $78{ }^{\circ} \mathrm{C}$ and $140{ }^{\circ} \mathrm{C}$ as a function of reaction time. Values are mean \pm standard deviation (SD) $(n=9)$; (B) Effect of potassium carbonate content on the WPG of VA-acetylated slicewood by the reaction at $140{ }^{\circ} \mathrm{C}$ for $6 \mathrm{~h}$. 
In addition, Figure 1B shows the WPG of the VA-acetylated slicewood with different PC contents at $140{ }^{\circ} \mathrm{C}$ for $6 \mathrm{~h}$. The results revealed that the WPG of the VA-acetylated slicewood without catalyst was only $2 \%$. As suggested by Çetin and Ozmen [11], Çetin et al. [20], and Jebrane and Sèbe [12], the VA-acetylated slicewood without catalyst gained hardly any weight. However, the WPG of VA-acetylated slicewood increases significantly to $5-9 \%$ when the PC content increased to $1 \%$, and then the WPG increases with increasing PC contents up to $5 \%$. This phenomenon can be explained that the addition of catalyst improves significantly the efficiency of the acetylation. Once the PC content exceeded 5\%, there was no further increased in the WPG. Accordingly, the 5\% of catalyst content was an optimum condition for the wood acetylation in this study.

\subsection{WPG, MOE, and MOR of VA-Acetylated Slicewood}

The WPG, modulus of elasticity (MOE), and modulus of rupture (MOR) of the VA-acetylated slicewood with two different catalysts, PC and PA, are shown in Table 1 as a function of the reaction time. The WPG of the VA-acetylated slicewood increased with the reaction time for both catalysts. At a reaction time of $0 \mathrm{~h}$ (i.e., the time point at which the reaction temperature reached $140{ }^{\circ} \mathrm{C}$ ), the WPG of VA-acetylated slicewood with PC and PA was $-1.4 \%$ and $-3.5 \%$, respectively. This phenomenon is likely caused by the degradation and leaching of wood components (hemicellulose and lignin) during immersion of the wood in the alkaline catalyst solutions, leading to a mass loss of wood. In addition, the WPG of VA-acetylated slicewood with PC (pH 11.6) increased to $11.3 \%$ at the reaction time of $6 \mathrm{~h}$, and then level off. In contrast, the WPG of VA-acetylated slicewood with PA ( $\mathrm{pH} 8.4)$ increased progressively with increasing the reaction time. However, the VA-acetylated slicewood with PC exhibited higher WPG than that with PA at all reaction time points. These results showed that PC as catalyst is more efficient than PA to acetylate wood with VA; similar result was observed by Çetin et al. [20].

Table 1. The weight percent gain (WPG), modulus of elasticity (MOE), and modulus of rupture (MOR) of vinyl acetate (VA)-acetylated slicewood with two different catalysts by the reaction at $140^{\circ} \mathrm{C}$ for $0-24 \mathrm{~h}$.

\begin{tabular}{|c|c|c|c|c|c|c|}
\hline \multirow{2}{*}{$\begin{array}{l}\text { Reaction } \\
\text { Time (h) }\end{array}$} & \multicolumn{3}{|c|}{ Potassium Carbonate (5\%) } & \multicolumn{3}{|c|}{ Potassium Acetate (5\%) } \\
\hline & WPG (\%) & MOE (GPa) & MOR (MPa) & WPG (\%) & MOE (GPa) & MOR (MPa) \\
\hline Control & - & $6.5 \pm 0.4^{\mathrm{a}}$ & $79 \pm 14^{\mathrm{a}}$ & - & $6.5 \pm 0.4^{\mathrm{a}}$ & $79 \pm 14^{\mathrm{a}}$ \\
\hline 0 & $-1.4 \pm 0.4 \mathrm{e}$ & $6.6 \pm 1.3^{a}$ & $91 \pm 18^{a}$ & $\begin{array}{c}-3.5 \pm 1.1 \\
\mathrm{e}\end{array}$ & $6.9 \pm 1.0^{a}$ & $100 \pm 20^{a}$ \\
\hline 0.5 & $0.9 \pm 1.3^{\mathrm{d}}$ & $5.8 \pm 0.6^{\mathrm{a}}$ & $80 \pm 2^{a}$ & $-0.7 \pm 0.8$ & $6.1 \pm 1.1^{\mathrm{a}}$ & $78 \pm 18^{a}$ \\
\hline 1 & $4.4 \pm 1.6^{\mathrm{c}}$ & $5.8 \pm 0.9^{\mathrm{a}}$ & $80 \pm 14^{a}$ & $0.2 \pm 0.8^{\mathrm{d}}$ & $6.5 \pm 0.9^{a}$ & $105 \pm 17^{a}$ \\
\hline 3 & $9.0 \pm 1.2^{b}$ & $5.6 \pm 0.6^{\mathrm{a}}$ & $94 \pm 33^{\mathrm{a}}$ & $3.6 \pm 1.3^{c}$ & $5.1 \pm 2.5^{\mathrm{a}}$ & $70 \pm 33^{a}$ \\
\hline 6 & $11.3 \pm 1.2^{\mathrm{a}}$ & $6.7 \pm 1.2^{\mathrm{a}}$ & $89 \pm 24^{a}$ & $9.4 \pm 1.1^{\mathrm{b}}$ & $5.1 \pm 1.3^{a}$ & $78 \pm 13^{a}$ \\
\hline 24 & $13.4 \pm 1.9^{\mathrm{a}}$ & $5.5 \pm 0.8^{\mathrm{a}}$ & $76 \pm 20^{a}$ & $12.9 \pm 1.1^{\mathrm{a}}$ & $6.6 \pm 1.4^{\mathrm{a}}$ & $88 \pm 23^{a}$ \\
\hline
\end{tabular}

Values are the means \pm standard deviation (SD) $(n=9)$. Different superscript letters within a column indicate significant differences at $p<0.05$.

Table 1 also shows that there were no significant differences in MOE and MOR values between unmodified and acetylated slicewood for both catalysts used. This result revealed that the bending properties of the VA-acetylated slicewood were not influenced by the degree of modification and the type of catalyst used in this study. As suggested by Birkinshaw and Hale [21] and Rowell and Banks [22], acetylation with AA did not significantly affect the mechanical properties of the softwoods (pine, lime, spruce, and larch). 


\subsection{Functional Groups and Calibrated WPG of VA-Acetylated Slicewood}

Figure 2 shows the ATR-FTIR spectrum of VA-acetylated slicewood with two catalysts at various reaction time. Regardless of catalyst type, the increase in the absorption bands of acetyl group at $1736 \mathrm{~cm}^{-1}\left(-\mathrm{OCOCH}_{3}, \mathrm{C}=\mathrm{O}\right), 1370 \mathrm{~cm}^{-1}\left(-\mathrm{OCOCH}_{3}, \mathrm{C}-\mathrm{H}\right)$, and $1251 \mathrm{~cm}^{-1}\left(-\mathrm{OCOCH}_{3}, \mathrm{C}-\mathrm{O}\right)$ were observed after the VA acetylation. Additionally, the intensity of these absorption bands increased significantly with increasing reaction time. This result confirms that slicewood was successfully acetylated with vapor phase VA using PC or PA as catalyst. Fávaro et al. [23], Hung and Wu [24], and Khalil et al. [25] also reported a similar increasing trend of FTIR spectrum for AA-acetylated woody materials. Compared with different catalysts used, it can be seen that the signal intensity of the acetyl group of VA-acetylated slicewood with PC (Figure 2A) was higher than that with PA (Figure 2B). This phenomenon agreed with results of the WPG of the VA-acetylated slicewood, and again confirmed that the PC as catalyst is more efficient than PA to acetylate slicewood with VA.

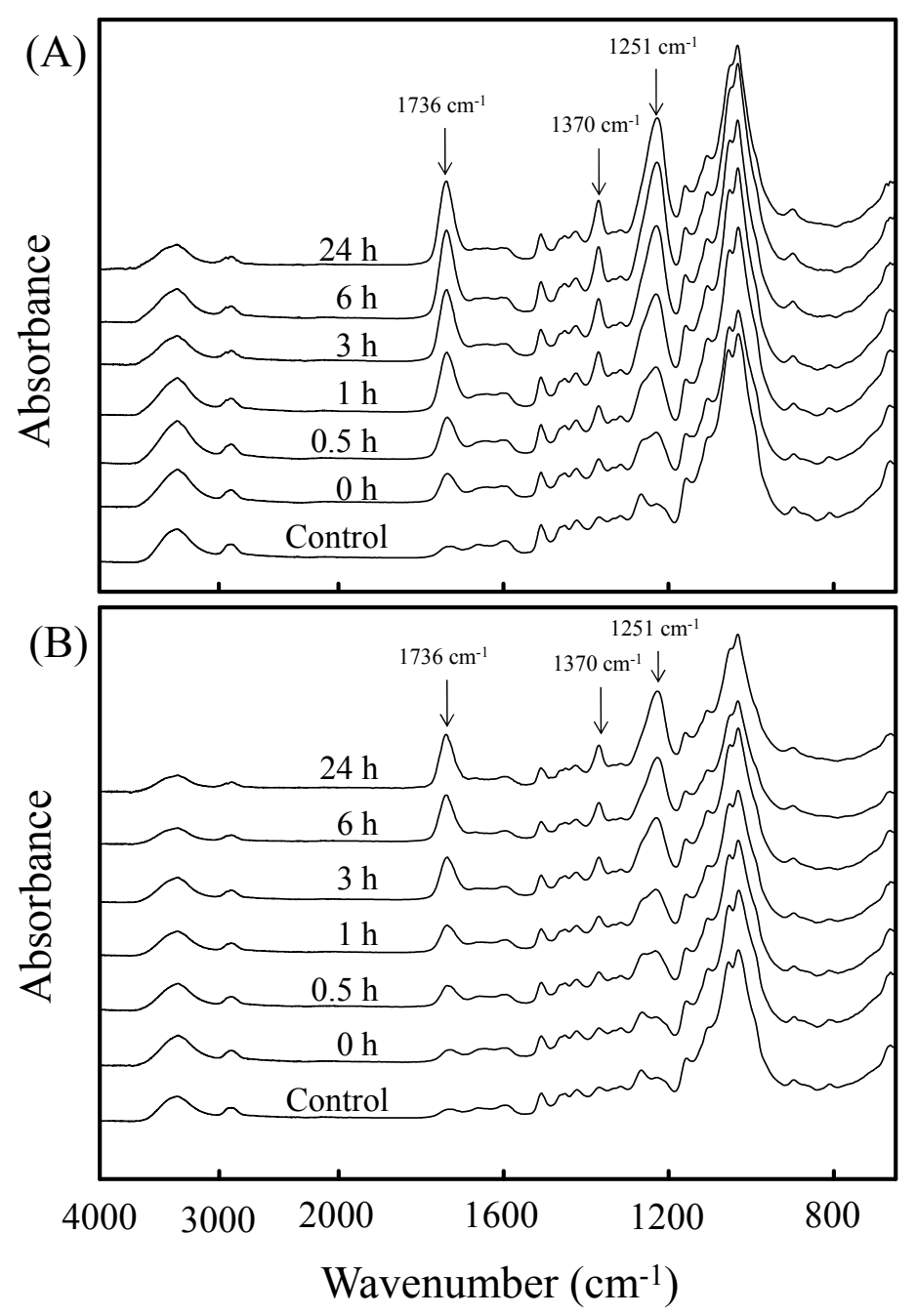

Figure 2. The attenuated total reflectance Fourier transform infrared (ATR-FTIR) spectra of VA-acetylated slicewood with potassium carbonate (PC) (A) and potassium acetate (PA) (B) as a catalyst at various reaction time.

Furthermore, the WPG of VA-acetylated slicewood with PC or PA calculated by weight method may be underestimated because alkali-soluble extractives of wood components could be leaching during pretreatment with catalyst solutions. To overcome this problem, the relationship between the WPG of non-pretreatment AA-acetylated slicewood and their FTIR absorption intensities of acetyl 
ester group at $1736 \mathrm{~cm}^{-1}$ was further investigated to calibrate the WPG of VA-acetylated slicewood.

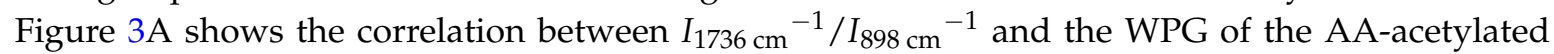
slicewood. Linear regression analysis revealed a highly linear correlation $\left(R^{2}=0.949\right)$ between the two selected items. This result indicated that the WPG of acetylated wood could be accurately evaluated by the FTIR method. Therefore, the calibrated WPG (cWPG) of VA-acetylated slicewood was evaluated

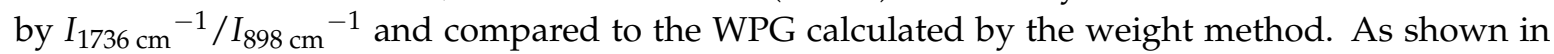
Figure 3B, it was found that the slope of linear regression $\left(R^{2}=0.814\right)$ between WPG and cWPG of VA-acetylated slicewood was approximately 0.8 . In other words, the WPG of VA-acetylated slicewood by the weight method was underestimated by $20 \%$.
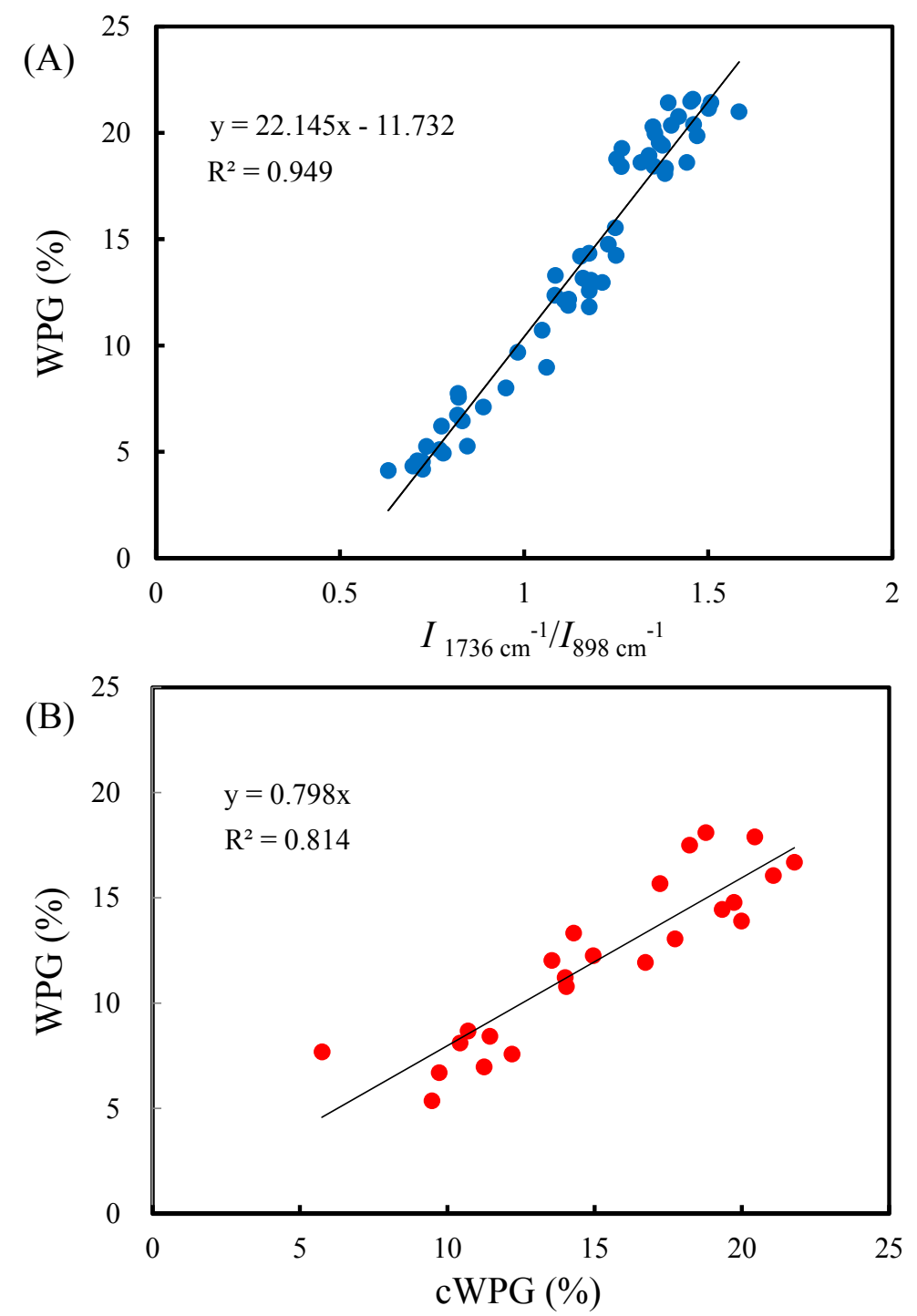

Figure 3. The correlations between the intensity of $I_{1736 \mathrm{~cm}-1} / I_{898 \mathrm{~cm}-1}$ and WPG of acetic anhydride (AA)-acetylated slicewood (A) and between the WPG and calibrated WPG (cWPG) of VA-acetylated slicewood (B) by vapor phase reaction for $6 \mathrm{~h}$.

\subsection{Reactive Characteristics of VA-Acetylated Slicewood}

In this study, solid state $\mathrm{CP} / \mathrm{MAS}{ }^{13} \mathrm{C}-\mathrm{NMR}$ was used to elucidate the reactive characteristics of slicewood before and after VA acetylation. Figure 4 illustrates various characteristic carbohydrate patterns, including C1 (105.2 ppm), C4 (88.9 ppm and 83.3 ppm), C2 (75.0 ppm), C3, C5 (72.4 ppm), and C6 (65.3 ppm and $62.7 \mathrm{ppm})$ for the unmodified slicewood $[7,10,24,26]$. 


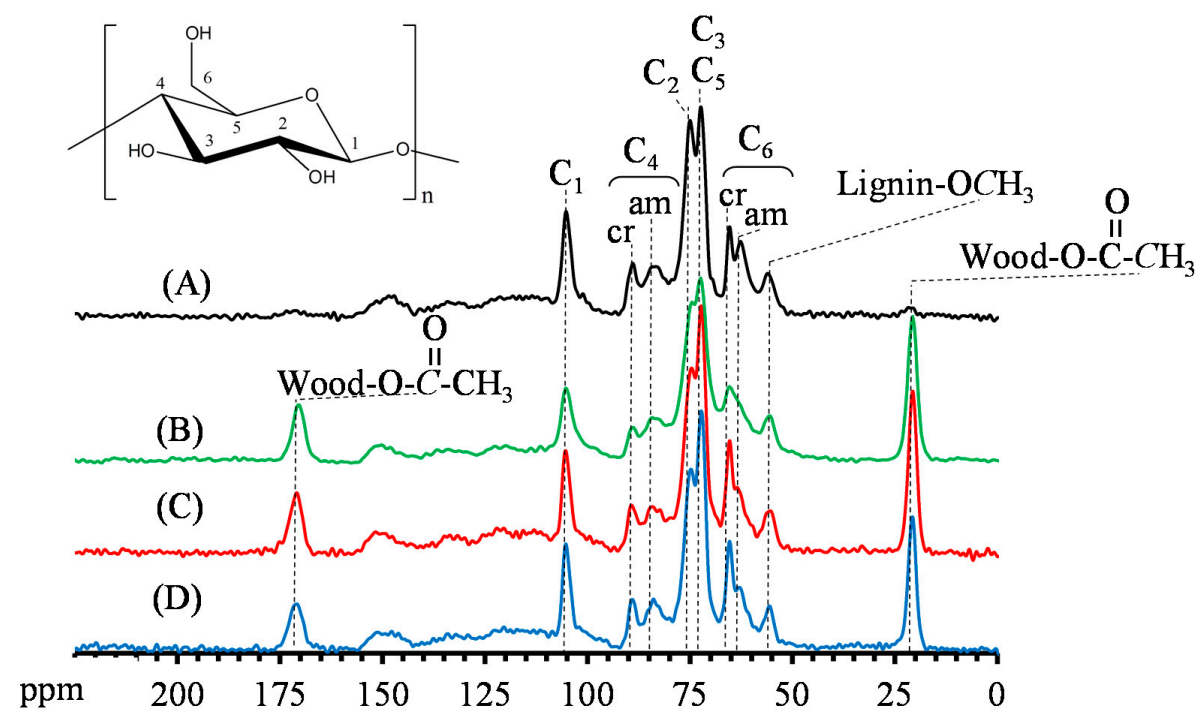

Figure 4. Solid state carbon-13 nuclear magnetic resonance $\left({ }^{13} \mathrm{C}-\mathrm{NMR}\right)$ spectra of unmodified slicewood (A), AA-acetylated slicewood (WPG 21\%) (B), and VA-acetylated slicewood (cWPG 18\%) with PC (C) and PA (D).

The signals of hemicellulose carbons were also found to resonate in the same field as that of the cellulose carbons, meaning that it could not be precisely identified among them [10]. The chemical shift at $56.1 \mathrm{ppm}$ and the broad signal between 125 and $160 \mathrm{ppm}$ corresponded to the methoxy groups and aromatic rings of lignin, respectively. In addition, the peaks at 170.9 and $20.7 \mathrm{ppm}$, which were assigned to the acetyl group, were also found in all the spectra from the AA- and VA-acetylated slicewood with all the catalyst. However, the intensity of the peaks at 75.0 (C2) and 62.7 (amorphous C6) ppm decreased and shifted downfield after acetylation, whereas there was no significant change observed at $72.4 \mathrm{ppm}(\mathrm{C} 3)$. Compared with the AA-acetylated slicewood, the solid state ${ }^{13} \mathrm{C}-\mathrm{NMR}$ spectra of VA-acetylated slicewood exhibited a remarkable decrease in the signal intensity of the C2 position $(75.0 \mathrm{ppm})$ for the VA-acetylated slicewood. In contrast, the signal intensity of amorphous C6 (62.7 ppm) of VA-acetylated slicewood was higher than that of AA-acetylated one. These results indicated that the order of the reactivity of the cellulose hydroxyl groups was $\mathrm{C} 2-\mathrm{OH}>\mathrm{C} 6-\mathrm{OH}>$ $\mathrm{C} 3-\mathrm{OH}$ when the slicewood was modified with VA, while in the case of AA acetylation, the order of the reactivity was $\mathrm{C} 6-\mathrm{OH}>\mathrm{C} 2-\mathrm{OH}>\mathrm{C} 3-\mathrm{OH}$. Similar results were also reported by Jebrane and Sèbe [12]. In addition, there were no significantly differences between the ${ }^{13} \mathrm{C}-\mathrm{NMR}$ spectra of VA-acetylated slicewood with PC and PA. This result implied that the accessibility of the modifying agent for VA acetylation was independent of the types of catalysts used in this study.

\subsection{Viscoelastic Properties of Acetylated Slicewood}

To understand the difference in viscoelastic properties of slicewood after acetylation, the dynamic mechanical analysis (DMA) was carried out in this study. As shown in Figure 5A, the $E^{\prime}$ retention ratio of acetylated slicewood was significantly different from the unmodified slicewood. The $E^{\prime}$ retention ratio of AA- and VA-acetylated slicewood was higher than that of unmodified slicewood (control) at temperature below $150{ }^{\circ} \mathrm{C}$. However, all the acetylated slicewood exhibited a dramatic decrease in the $E^{\prime}$ retention ratio as the temperature increased beyond $150{ }^{\circ} \mathrm{C}$. Obataya et al. suggest that some of hydrogen bonds between the amorphous molecules are severed as the acetyl groups (an internal plasticizer) are introduced into the system, resulting in an increase in the mobility of the amorphous molecules at elevated temperature [27]. 

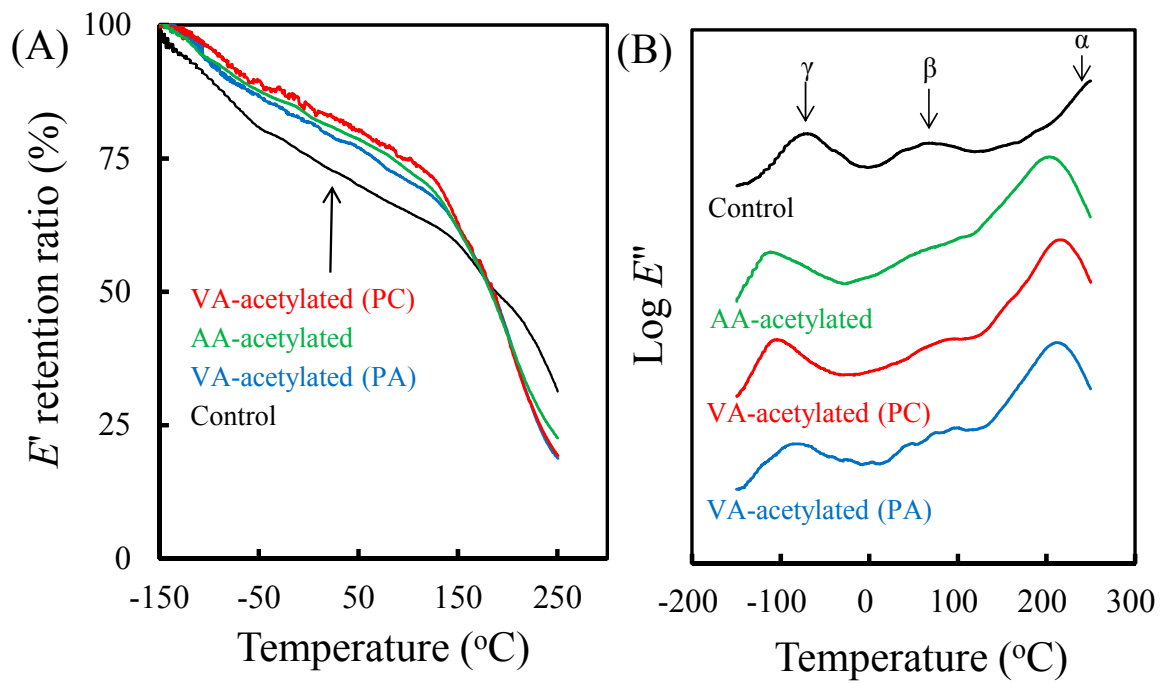

Figure 5. The storage modulus $\left(E^{\prime}\right)$ retention ratio $(\mathbf{A})$ and loss modulus $\left(E^{\prime \prime}\right)(\mathbf{B})$ of unmodified slicewood, AA-acetylated slicewood (WPG 21\%), and VA-acetylated slicewood (cWPG 18\%) with PC and PA.

On the other hand, Figure $5 \mathrm{~B}$ reveals that the $E^{\prime \prime}$ of the unmodified slicewood shows three distinct relaxation processes labeled $\alpha, \beta$, and $\gamma$ in order of decreasing temperature, and which they are assigned to the micro-Brownian motions of lignocellulose polymers in the non-crystalline regions, the motions of lignin and/or lignin-hemicellulose complexes plasticized with water, and the motions of the methylol groups of the lignocellulose polymers in the amorphous zones, respectively [6,27-29]. It was observed that both $\alpha$ and $\gamma$ transitions of all the acetylated slicewood exhibited the same tendency, i.e., shifting to lower temperature. Again, this result indicated that the lignocellulose polymers mobility was improved in the non-crystalline regions because some of the hydrogen bonds between the amorphous molecules were severed with the introduction of the acetyl groups. In addition, comparison with the unmodified slicewood, the $\beta$ transition of all the acetylated slicewood was remarkably vanished, which revealed a reduction in the hygroscopicity of the slicewood after acetylation. Meanwhile, a new $\beta$ transition appeared at around $70{ }^{\circ} \mathrm{C}$ for the acetylated slicewood, especially treatment with VA. A similar result was also reported by Jebrane et al. [7], who suggested that cellulose sites in wood were more attacked by VA than by AA. However, there are no significant differences in the viscoelastic properties between PC- and PA-catalyzed acetylations of slicewood.

\subsection{Thermal Decomposition Kinetics of Acetylated Slicewood}

Figure 6 shows the TGA curves of unmodified slicewood (control), AA-acetylated slicewood, and VA-acetylated slicewood with two different catalysts. The TGA curve of unmodified slicewood exhibited a gradually increasing weight loss above $200{ }^{\circ} \mathrm{C}$ and a maximum weight loss was obtained around $350{ }^{\circ} \mathrm{C}$. In contrast, the pyrolysis of the AA- and VA-acetylated slicewood was delayed ca. $10{ }^{\circ} \mathrm{C}$, compared to the unmodified slicewood, indicating that the thermal stability of slicewood could be effectively enhanced through acetylation. A similar result was obtained by $\mathrm{Xu}$ et al. [13], Özmen et al. [14], and Wei et al. [15]. Additionally, the solid residue of all acetylated slicewood $(15 \%-17 \%)$ was lower than the unmodified slicewood $(19.3 \%)$ at $600{ }^{\circ} \mathrm{C}$, and it is possible that the acyl groups in the acetylated wood were eliminated with the volatile products and did not convert to the char [5].

To further understand the thermal decomposition kinetics of unmodified and acetylated slicewood, the model-free iso-conversional methods were used. The plots of the iso-conversional Friedman, Flynn-Wall-Ozawa (F-W-O), modified Coats-Redfern (C-R), and Starink methods describe a general trend in the $E_{\mathrm{a}}$. As an example, typical plots based on the models F-W-O, modified C-R, Friedman, 
and Starink for unmodified slicewood are presented in Figure 7. The slopes of the fitted lines between $10 \%$ and $70 \%$ conversion were nearly parallel, indicating the approximate $E_{\mathrm{a}}$ at different conversion methods. The acetylated slicewood plots are similar to those presented in Figure 7 (not shown). As reported by Yao et al., a single possible reaction mechanism takes place between $10 \%$ and $70 \%$ conversion rates in natural fibers, which might provide a simplified and more meaningful method to explain the thermal decomposition behavior of natural fibers [16]. Hence, in this study, the apparent $E_{\mathrm{a}}$ was estimated in this conversion range. The correlation coefficient $\left(R^{2}\right)$ and the $E_{\mathrm{a}}$ values calculated from the above-mentioned methods are listed in Table 2.

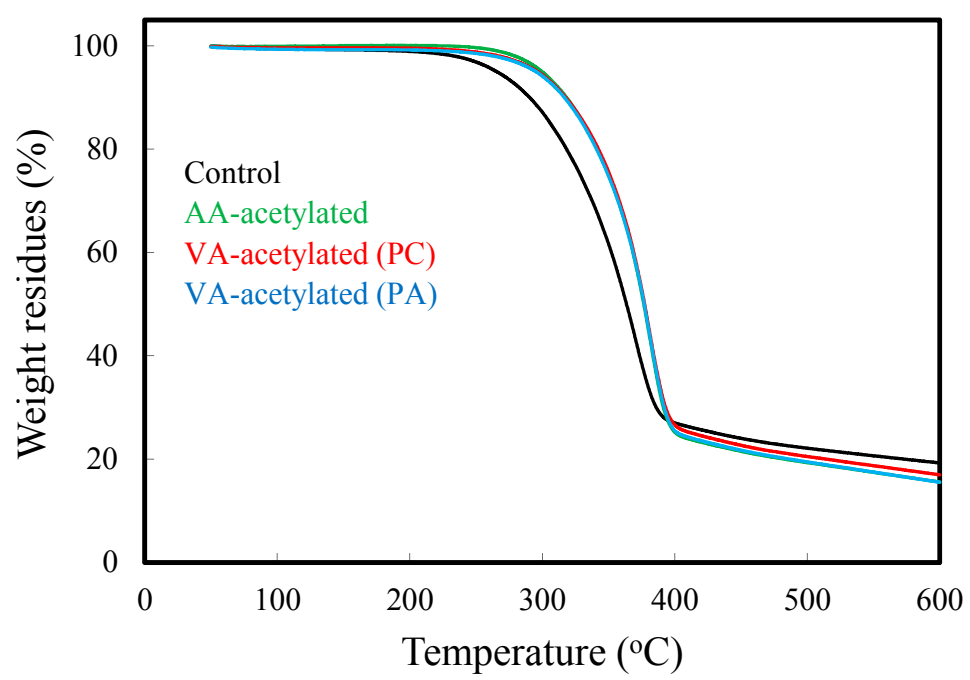

Figure 6. Thermogravimetric curves of unmodified slicewood, AA-acetylated slicewood (WPG 18\%), and VA-acetylated slicewood (cWPG 18\%) with PC and PA.
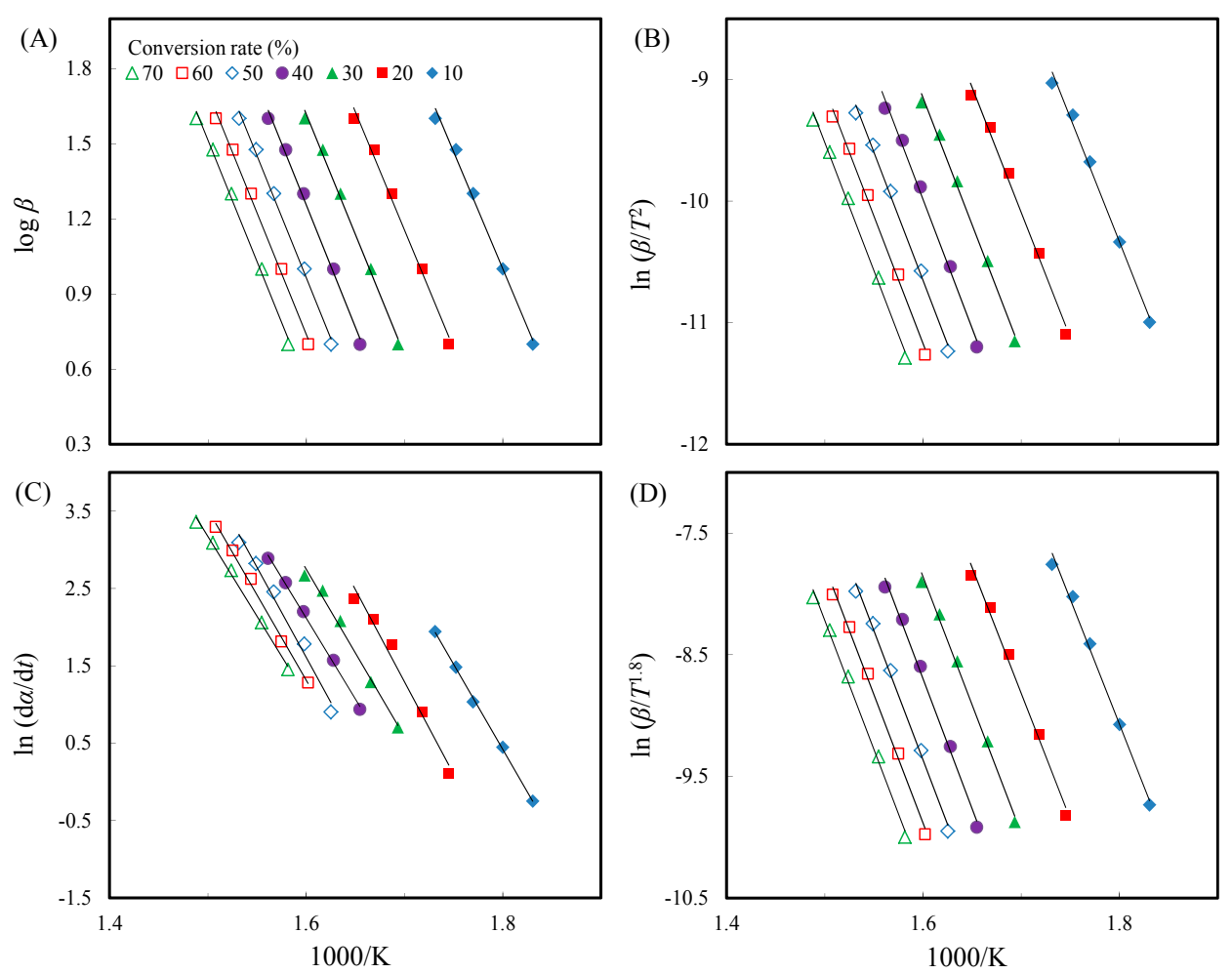

Figure 7. Typical iso-conversional plots of Flynn-Wall-Ozawa (F-W-O) (A); modified Coats-Redfern (C-R) (B); Friedman (C); and Starink (D) methods for unmodified slicewood. 
Table 2. Apparent activation energy and reaction order of unmodified slicewood, acetic anhydride (AA)-acetylated slicewood (WPG 18\%), and vinyl acetate (VA)-acetylated slicewood (cWPG 18\%) with potassium carbonate (PC) and potassium acetate (PA) calculated by the methods of Flynn-Wall-Ozawa (F-W-O), modified Coats-Redfern (C-R), Friedman, Starink, and Avrami.

\begin{tabular}{|c|c|c|c|c|c|c|c|c|c|c|}
\hline \multirow{2}{*}{ Slicewood } & \multirow{2}{*}{ Methods } & \multirow{2}{*}{ Units } & \multicolumn{8}{|c|}{ Conversion Rates } \\
\hline & & & $10 \%$ & $20 \%$ & $30 \%$ & $40 \%$ & $50 \%$ & $60 \%$ & $70 \%$ & Mean \\
\hline \multirow{10}{*}{$\begin{array}{l}\text { Unmodified } \\
\text { (Control) }\end{array}$} & F-W-O & $E_{\mathrm{a}}(\mathrm{kJ} / \mathrm{mol})$ & 170 & 172 & 175 & 178 & 177 & 176 & 177 & 175 \\
\hline & & $R^{2}$ & 0.994 & 0.992 & 0.995 & 0.995 & 0.996 & 0.996 & 0.996 & - \\
\hline & Modified C-R & $E_{\mathrm{a}}(\mathrm{kJ} / \mathrm{mol})$ & 169 & 171 & 174 & 176 & 176 & 175 & 175 & 174 \\
\hline & & $R^{2}$ & 0.993 & 0.991 & 0.995 & 0.995 & 0.996 & 0.996 & 0.995 & - \\
\hline & Friedman & $E_{\mathrm{a}}(\mathrm{kJ} / \mathrm{mol})$ & 183 & 198 & 180 & 174 & 193 & 183 & 172 & 183 \\
\hline & & $R^{2}$ & 0.999 & 0.978 & 0.989 & 0.998 & 0.984 & 0.996 & 0.996 & - \\
\hline & Starink & $E_{\mathrm{a}}(\mathrm{kJ} / \mathrm{mol})$ & 170 & 172 & 175 & 177 & 176 & 175 & 176 & 174 \\
\hline & & $R^{2}$ & 0.993 & 0.991 & 0.995 & 0.995 & 0.996 & 0.996 & 0.996 & - \\
\hline & Avrami & Reac. order & 0.42 & 0.41 & 0.41 & 0.41 & 0.43 & 0.46 & 0.50 & 0.43 \\
\hline & & $R^{2}$ & 0.984 & 0.992 & 0.992 & 0.996 & 0.997 & 0.999 & $\approx 1$ & - \\
\hline \multirow[t]{10}{*}{ AA-acetylated } & F-W-O & $E_{\mathrm{a}}(\mathrm{kJ} / \mathrm{mol})$ & 182 & 191 & 198 & 202 & 201 & 199 & 199 & 196 \\
\hline & & $R^{2}$ & 0.999 & $\approx 1$ & 0.999 & 0.999 & 0.999 & $\approx 1$ & $\approx 1$ & - \\
\hline & Modified C-R & $E_{\mathrm{a}}(\mathrm{kJ} / \mathrm{mol})$ & 181 & 190 & 197 & 202 & 200 & 198 & 199 & 195 \\
\hline & & $R^{2}$ & 0.999 & $\approx 1$ & 0.999 & 0.999 & 0.999 & $\approx 1$ & 0.999 & - \\
\hline & Friedman & $E_{\mathrm{a}}(\mathrm{kJ} / \mathrm{mol})$ & 201 & 232 & 205 & 229 & 191 & 192 & 206 & 208 \\
\hline & & $R^{2}$ & 0.980 & 0.980 & 0.997 & 0.992 & 0.998 & 0.999 & 0.997 & - \\
\hline & Starink & $E_{\mathrm{a}}(\mathrm{kJ} / \mathrm{mol})$ & 182 & 191 & 198 & 202 & 201 & 198 & 199 & 196 \\
\hline & & $R^{2}$ & 0.999 & $\approx 1$ & 0.999 & 0.999 & 0.999 & $\approx 1$ & 0.999 & - \\
\hline & Avrami & Reac. order & 0.57 & 0.54 & 0.50 & 0.49 & 0.52 & 0.56 & 0.61 & 0.54 \\
\hline & & $R^{2}$ & 0.997 & 0.998 & 0.998 & 0.999 & $\approx 1$ & 0.997 & 0.994 & - \\
\hline \multirow{10}{*}{$\begin{array}{l}\text { VA-acetylated } \\
\text { (PC) }\end{array}$} & F-W-O & $E_{\mathrm{a}}(\mathrm{kJ} / \mathrm{mol})$ & 175 & 186 & 194 & 201 & 202 & 201 & 203 & 195 \\
\hline & & $R^{2}$ & 0.988 & 0.998 & 0.999 & $\approx 1$ & $\approx 1$ & $\approx 1$ & $\approx 1$ & - \\
\hline & Modified C-R & $E_{\mathrm{a}}(\mathrm{kJ} / \mathrm{mol})$ & 174 & 186 & 194 & 201 & 202 & 201 & 203 & 194 \\
\hline & & $R^{2}$ & 0.987 & 0.997 & 0.999 & 0.999 & $\approx 1$ & $\approx 1$ & $\approx 1$ & - \\
\hline & Friedman & $E_{\mathrm{a}}(\mathrm{kJ} / \mathrm{mol})$ & 172 & 206 & 202 & 196 & 205 & 206 & 213 & 200 \\
\hline & & $R^{2}$ & 0.980 & 0.995 & 0.996 & 0.999 & 0.999 & 0.996 & 0.999 & - \\
\hline & Starink & $E_{\mathrm{a}}(\mathrm{kJ} / \mathrm{mol})$ & 175 & 186 & 194 & 201 & 202 & 201 & 203 & 195 \\
\hline & & $R^{2}$ & 0.987 & 0.997 & 0.999 & 0.999 & $\approx 1$ & $\approx 1$ & $\approx 1$ & - \\
\hline & Avrami & Reac. order & 0.51 & 0.51 & 0.48 & 0.52 & 0.57 & 0.62 & 0.65 & 0.55 \\
\hline & & $R^{2}$ & 0.926 & 0.989 & 0.996 & 0.998 & 0.998 & 0.997 & 0.996 & - \\
\hline \multirow{10}{*}{$\begin{array}{c}\text { VA-acetylated } \\
\text { (PA) }\end{array}$} & $\mathrm{F}-\mathrm{W}-\mathrm{O}$ & $E_{\mathrm{a}}(\mathrm{kJ} / \mathrm{mol})$ & 163 & 173 & 183 & 189 & 194 & 193 & 194 & 184 \\
\hline & & $R^{2}$ & 0.995 & 0.995 & 0.995 & 0.995 & 0.996 & 0.996 & 0.994 & - \\
\hline & Modified C-R & $E_{\mathrm{a}}(\mathrm{kJ} / \mathrm{mol})$ & 161 & 172 & 182 & 189 & 194 & 193 & 193 & 183 \\
\hline & & $R^{2}$ & 0.995 & 0.994 & 0.995 & 0.995 & 0.995 & 0.995 & 0.993 & - \\
\hline & Friedman & $E_{\mathrm{a}}(\mathrm{kJ} / \mathrm{mol})$ & 157 & 170 & 200 & 193 & 195 & 186 & 201 & 186 \\
\hline & & $R^{2}$ & 0.987 & 0.989 & 0.997 & 0.995 & 0.995 & 0.991 & 0.991 & - \\
\hline & Starink & $E_{\mathrm{a}}(\mathrm{kJ} / \mathrm{mol})$ & 162 & 172 & 182 & 189 & 194 & 193 & 193 & 184 \\
\hline & & $R^{2}$ & 0.995 & 0.994 & 0.995 & 0.995 & 0.995 & 0.995 & 0.994 & - \\
\hline & Avrami & Reac. order & 0.59 & 0.58 & 0.55 & 0.53 & 0.55 & 0.59 & 0.63 & 0.57 \\
\hline & & $R^{2}$ & 0.995 & 0.995 & 0.996 & 0.996 & 0.996 & 0.995 & 0.992 & - \\
\hline
\end{tabular}

As shown in Table 2, the $E_{\mathrm{a}}$ values of unmodified slicewood calculated by F-W-O method are between 170 and $178 \mathrm{~kJ} / \mathrm{mol}$ (at the conversion range of 10-70\%), and the $E_{\mathrm{a}}$ value increases with increasing conversion rate up to $40 \%$. As found by Yao et al., the average apparent $E_{\mathrm{a}}$ of natural fibers calculated between $10 \%$ and $60 \%$ by the F-W-O method was $171.5 \mathrm{~kJ} / \mathrm{mol}$ [16]. In the present study, the average apparent $E_{\mathrm{a}}$ of unmodified slicewood is $175 \mathrm{~kJ} / \mathrm{mol}$, which is in good agreement with the literature data. Moreover, the average apparent $E_{\mathrm{a}}$ of the acetylated slicewood was 196, 195, and $184 \mathrm{~kJ} / \mathrm{mol}$ for AA- (WPG 18\%), VA-acetylated slicewood (cWPG 18\%) with PC and PA, respectively. The $E_{\mathrm{a}}$ is defined as the minimum energy that must be overcome to start a chemical reaction [30]. As the $E_{\mathrm{a}}$ values increased, the minimum energy required to start the thermal decomposition was also elevated. Similar results from modified C-R, Friedman, and Starink methods also confirm this observation (Table 2). The average $E_{\mathrm{a}}$ values calculated in the conversion range of 
10-70\% were 174-183, 195-208, 194-200, and 183-186 kJ/mol for unmodified, AA-acetylated, and VA-acetylated slicewood with PC and PA, respectively. A statement of Brown et al. and Yao et al. should be remembered, according to which different kinetic analysis methods are complementary, rather than competitive [16,31]. Thus, a suitable apparent $E_{\mathrm{a}}$ range could be obtained by combining all observations in Table 2. Compared with different catalysts used, it can be seen that the average apparent $E_{\mathrm{a}}$ of VA-acetylated slicewood with PC was higher than that with PA. This result indicated that the VA-acetylated slicewood with PC exhibited more thermal stability than that with PA.

Moreover, to estimate the dependence of the reaction order $(n)$ on the decomposition temperature during the major thermal decomposition process, seven decomposition temperatures were employed at five heating rates $(5,10,20,30$, and $40 \mathrm{~K} / \mathrm{min})$. The seven decomposition temperatures were the temperature of conversion between $10 \%$ and $70 \%$ at a heating rate of $5 \mathrm{~K} / \mathrm{min}$. Based on the Avrami theory, the regression lines of the unmodified and all acetylated slicewood are illustrated in Figure 8 . The calculated reaction order and corresponding $R^{2}$ values are also presented in Table 2 . It is remarkable that most $R^{2}$ values are higher than 0.99. Thus, the Avrami theory is suitable to evaluate the reaction order of unmodified and acetylated slicewood. The reaction order was range of $0.41-0.50$, 0.49-0.61, 0.48-0.65, and 0.53-0.63 for unmodified, AA-acetylated, and VA-acetylated slicewood with PC and PA, respectively (Table 2). It has been reported that the reaction orders of wood waste, corn straw, and rice husks are $0.420,0.365$, and 0.539 , respectively $[17,32]$. The reaction order of unmodified slicewood was found in a similar range as the literature. In addition, the reaction order of slicewood increased after AA or VA acetylation, indicating that introduction of acetyl groups into the wood may have changed the thermal decomposition path. Accordingly, the acetylation improves the thermal stability of slicewood, and the thermal stability of VA-acetylated slicewood with PC was better than that with PA.
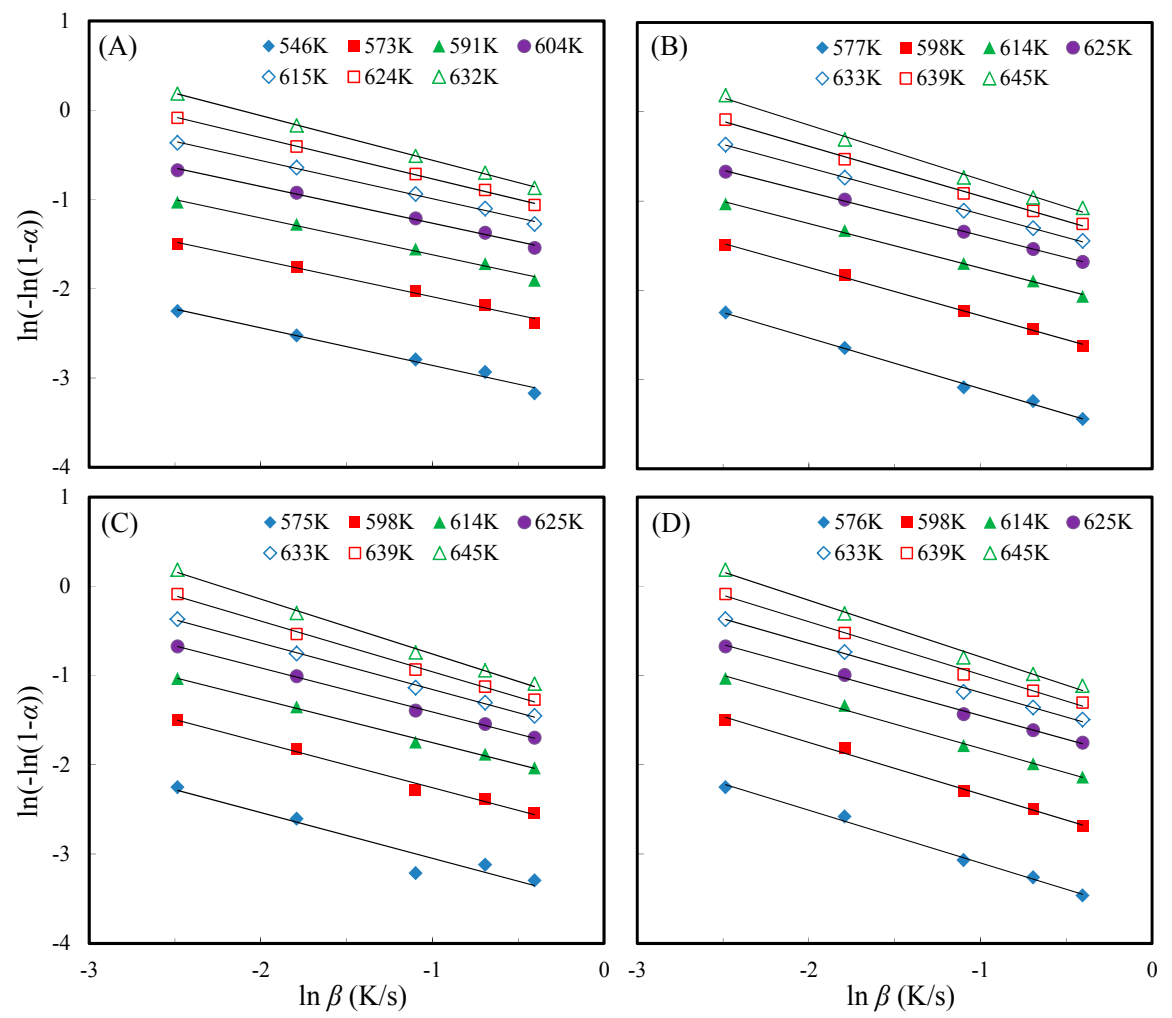

Figure 8. Regression lines to reaction order proposed by Avrami theory for unmodified slicewood (A); AA-acetylated slicewood (WPG 18\%) (B); and VA-acetylated slicewood (cWPG 18\%) with PC (C) and PA (D). 


\section{Conclusions}

Alkali-catalyzed acetylation with VA by vapor phase reaction could be used as an alternative process for wood acetylation, and in which the optimal catalyst loading was $5 \%$. There are no significant differences in bending and viscoelastic properties between PA- and PC-catalyzed acetylations of slicewood. The reactivity of the hydroxyl groups in the cellulose was sensitive at the $\mathrm{C} 2$ reactive site for the alkali-catalyzed acetylation of slicewood with VA, while the $\mathrm{C} 6$ reactive site was sensitive for the conventional acetylation with AA. The TG curves of the acetylated slicewood shifted to a higher temperature field compared to the unmodified slicewood. The average apparent $E_{\mathrm{a}}$ of the acetylated slicewood was higher than that of the unmodified slicewood, and the VA-acetylated slicewood with PC has higher apparent $E_{\mathrm{a}}$ than that with PA. For the range of conversion rates (10-70\%) investigated, the reaction order was $0.41-0.50,0.49-0.61,0.48-0.65$, and $0.53-0.63$ for unmodified, AA-acetylated, and VA-acetylated slicewood with PC and PA, respectively. These results indicate that the thermal stability of slicewood could be enhanced by vapor phase VA acetylation with an alkaline catalyst.

Acknowledgments: This work was financially supported by a research grant from the Forestry Bureau of the Council of Agriculture (101AS-13.4.4-FB-e1(3)) and partially by the Ministry of Science and Technology, Taiwan (NSC 102-2628-B-005-006-MY3).

Author Contributions: Ke-Chang Hung, Chen-Ning Yang, and Jyh-Horng Wu conceived and designed the experiments; Ke-Chang Hung, Chen-Ning Yang, Teng-Chun Yang, Tung-Lin Wu, Yong-Long Chen, and Jyh-Horng Wu carried out the laboratory experiments; Ke-Chang Hung and Jyh-Horng Wu analyzed the data, interpreted the results, prepared figures, and wrote the manuscript. All authors read and approved the final manuscript.

Conflicts of Interest: The authors declare no conflict of interest.

\section{References}

1. Hoadley, R.B. Understanding Wood: A Craftsman's Guide to Wood Technology; The Taunton Press: Newtown, CT, USA, 2000.

2. Srinivas, K.; Pandey, K.K. Effect of heat treatment on color changes, dimensional stability, and mechanical properties of wood. J. Wood Chem. Technol. 2012, 32, 304-316. [CrossRef]

3. Hill, C.A.S. Wood Modification: Chemical, Thermal and Other Processes; John Wiley \& Sons Ltd: Chichester, UK, 2006.

4. Wang, X.; Liu, J.; Chai, Y. Thermal, mechanical, and moisture absorption properties of wood- $\mathrm{TiO}_{2}$ composites prepared by a sol-gel process. Bioresources 2012, 7, 893-901.

5. Wu, J.-H.; Hsieh, T.-Y.; Lin, H.-Y.; Shiau, I.-L.; Chang, S.-T. Properties of wood plasticization with octanoyl chloride in a solvent-free system. Wood Sci. Technol. 2004, 37, 363-372. [CrossRef]

6. Jebrane, M.; Harper, D.; Labbé, N.; Sèbe, G. Comparative determination of the grafting distribution and viscoelastic properties of wood blocks acetylated by vinyl acetate or acetic anhydride. Carbohydr. Polym. 2011, 84, 1314-1320. [CrossRef]

7. Jebrane, M.; Pichavant, F.; Sèbe, G. A comparative study on the acetylation of wood by reaction with vinyl acetate and acetic anhydride. Carbohydr. Polym. 2011, 83, 339-345. [CrossRef]

8. Minato, K.; Shimizu, R.; Kawaguchi, S. Contribution of lignin to the reactivity of wood in chemical modification I: Influence of delignification on actylation. J. Wood Sci. 2007, 53, 218-222. [CrossRef]

9. Rowell, R.M. Chemical modification of wood: A short review. Wood Mater. Sci. Eng. 2006, 1, 29-33. [CrossRef]

10. Yang, C.-N.; Hung, K.-C.; Wu, T.-L.; Yang, T.-C.; Chen, Y.-L.; Wu, J.-H. Comparisons and characteristics of slicewood acetylation with acetic anhydride by liquid phase, microwave, and vapor phase reactions. Bioresources 2014, 9, 6463-6475. [CrossRef]

11. Çetin, N.S.; Ozmen, N. Acetylation of wood components and Fourier transform infra-red spectroscopy studies. Afr. J. Biotechnol. 2011, 10, 3091-3096.

12. Jebrane, M.; Sèbe, G. A novel simple route to wood acetylation by transesterification with vinyl acetate. Holzforschung 2007, 61, 143-147. [CrossRef]

13. Xu, C.; Leppänen, A.-S.; Eklund, P.; Holmlund, P.; Sjöholm, R.; Sundberg, K.; Willför, S. Acetylation and characterization of spruce (Picea abies) galactoglucomannans. Carbohyd. Res. 2010, 345, 810-816. [CrossRef] [PubMed] 
14. Özmen, N.; Çetin, N.S.; Mengeloğlu, F.; Birinci, E.; Karakuș, K. Effect of wood acetylation with vinyl acetate and anhydride on the properties of wood-plastic composites. Bioresources 2013, 8, 753-767. [CrossRef]

15. Wei, L.; McDonald, A.G.; Freitag, C.; Morrell, J.J. Effects of wood fiber esterification on properties, weatherability and biodurability of wood plastic composites. Polym. Degrad. Stabil. 2013, 98, 1348-1361. [CrossRef]

16. Yao, F.; Wu, Q.; Lei, Y.; Guo, W.; Xu, Y. Thermal decomposition kinetics of natural fibers: Activation energy with dynamic thermogravimetric analysis. Polym. Degrad. Stabil. 2008, 93, 90-98. [CrossRef]

17. Gai, C.; Dong, Y.; Zhang, T. The kinetic analysis of the pyrolysis of agricultural residue under non-isothermal conditions. Bioresour. Technol. 2013, 127, 298-305. [CrossRef] [PubMed]

18. Li, Y.; Du, L.; Kai, C.; Huang, R.; Wu, Q. Bamboo and high density polyethylene composite with heat-treated bamboo fiber: Thermal decomposition properties. Bioresources 2013, 8, 900-912. [CrossRef]

19. ASTM. Standard Test Methods for Flexural Properties of Unreinforced and Reinforced Plastics and Electrical Insulating Meterials; ASTM D790; ASTM: West Conshohocken, PA, USA, 2009.

20. Çetin, N.S.; Ozmen, N.; Birinci, E. Acetylation of wood with various catalysts. J. Wood Chem. Technol. 2011, 31, 142-153. [CrossRef]

21. Birkinshaw, C.; Hale, M.D. Mechanical properties and fungal resistance of acetylated fast grown softwoods. I. Small specimens. Ir. For. 2002, 59, 49-58.

22. Rowell, R.M.; Banks, W.B. Tensile strength and toughness of acetylated pine and lime flakes. Polym. Int. 1987, 19, 479-482. [CrossRef]

23. Fávaro, S.L.; Lopes, M.S.; Neto, A.G.V.C.; Santana, R.R.; Radovanovic, E. Chemical, morphological, and mechanical analysis of rice husk/post-consumer polyethylene composites. Compos. A Appl. Sci. Manuf. 2010, 41, 154-160. [CrossRef]

24. Hung, K.-C.; Wu, J.-H. Mechanical and interfacial properties of plastic composite panels made from esterified bamboo particles. J. Wood Sci. 2010, 56, 216-221. [CrossRef]

25. Khalil, H.P.S.A.; Bakare, I.O.; Khairul, A.; Issam, A.M.; Bhat, I. Effect of anhydride modification on the thermal stability of cultivated Acacia mangium. J. Wood Chem. Technol. 2011, 31, 154-171. [CrossRef]

26. Boonstra, M.G.; Pizzi, A.; Tekely, P.; Pendlebury, J. Chemical modification of Norway spruce and Scots pine. ${ }^{13} \mathrm{C}$ NMR CP-MAS study of the reactivity and reactions of polymeric wood components with acetic anhydride. Holzforschung 1996, 50, 215-220. [CrossRef]

27. Obataya, E.; Furuta, Y.; Gril, J. Dynamic viscoelastic properties of wood acetylated with acetic anhydride solution of glucose pentaacetate. J. Wood Sci. 2003, 49, 152-157. [CrossRef]

28. Backamn, A.C.; Lindberg, K.A.H. Differences in wood material responses for radial and tangential direction as measured by dynamic mechanical thermal analysis. J. Mater. Sci. 2001, 36, 3777-3783. [CrossRef]

29. Jiang, J.; Lu, J. Dynamic viscoelastic behavior of wood under drying conditions. Front. For. China 2009, 4, 374-379. [CrossRef]

30. Gao, J.; Kim, J.S.; Terziev, N.; Daniel, G. Decay resistance of softwoods and hardwoods thermally modified by the thermovouto type thermo-vacuum process to brown rot and white rot fungi. Holzforschung 2016, 70 , 877-884. [CrossRef]

31. Brown, M.E.; Maciejewski, M.; Vyazovkin, S.; Nomen, R.; Sempere, J.; Burnham, A. Computational aspects of kinetic analysis. Part A: The ICTAC kinetics project-data, methods and results. Thermochim. Acta 2000, 355, 125-143. [CrossRef]

32. Vuthaluru, H.B. Investigations into the pyrolytic behavior of coal/biomass blends using thermogravimetric analysis. Bioresour. Technol. 2004, 92, 187-195. [CrossRef] [PubMed]

(c) 2017 by the authors. Licensee MDPI, Basel, Switzerland. This article is an open access article distributed under the terms and conditions of the Creative Commons Attribution (CC BY) license (http://creativecommons.org/licenses/by/4.0/). 